\title{
A Q Methodology Study of Supervisee Roles Within a Counseling Practicum Course
}

\author{
Eric R. Baltrinic, Ryan M. Cook, Heather J. Fye
}

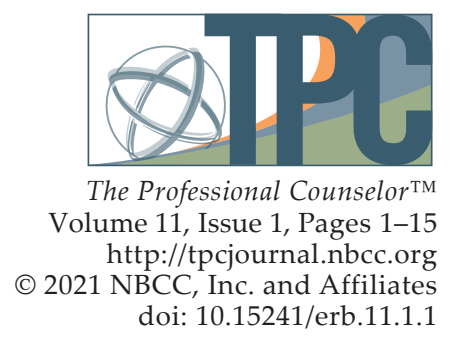

Counseling students often experience clinical supervision for the first time during their participation in practicum courses. Counseling practicum supervisees new to supervision rely on their supervisors to provide direction and structure in supervision experiences to help them grow professionally and personally. Yet little is known about how students view their roles as new supervisees. Supervisors can benefit from structuring and delivering their courses informed by new supervisees' perspectives on their roles. Accordingly, the authors conducted a $Q$ methodology study with a purposeful sample of seven counseling practicum students, a doctoral co-instructor, and a counseling practicum instructor engaged in a first-semester counseling practicum course. Principal components analysis with varimax rotation of $Q$-sort data revealed three factors depicting supervisee roles (i.e., Dutiful, Discerning, and Expressive Learners). Implications for applying findings to improve supervision instruction and student learning are discussed, including limitations and future research suggestions.

Keywords: counseling practicum supervisees, supervisee roles, $Q$ methodology, counseling practicum instructors, student learning

Supervision is generally understood as a relational and evaluative process between a senior and junior member of a profession, which is intended to foster the junior member's learning and professional skill development while also ensuring the welfare of clients they serve (Bernard \& Goodyear, 2019). Supervision is also a key pedagogical and curricular feature of counseling training programs (Council for Accreditation of Counseling and Related Educational Programs [CACREP], 2015) within which students develop into entry-level counselors. Although supervision is often considered a hierarchal relationship, supervisees are active participants in the supervision process (Stark, 2017). Thus, as part of counselor training, it is important for counseling students to understand what supervision is and what is expected of them (Bernard \& Goodyear, 2019). Counseling students' learning about the supervision process and supervisee roles commonly begins during their participation in field experience courses, the first of which is the counseling practicum course (CACREP, 2015). However, little is known about how counseling practicum supervisees come to understand their roles (Pearson, 2004) and, consequently, how counseling students use their understanding of roles to contribute to the learning process in supervision (Borders, 2019; Stark, 2017). This lack of understanding is compounded by a preponderance of supervision research grounded in expert perspectives and less so from the perspectives of counseling students new to supervision (Stark, 2017).

Thus, there are clear advantages to investigating counseling practicum supervisees' understanding of their supervisee roles, particularly while they are engaged in their first field experience (i.e., practicum) course. First, practicum experiences offer supervisees applied learning environments (CACREP, 2015) where they can apply prior learning under supervision to their work with actual clients (Moate et al., 2017). To that end, this is the first time that these novice supervisees are ethically responsible for their clients' care, which includes adequately conveying their professional needs to their supervisors

Eric R. Baltrinic, PhD, LPCC-S (OH), is an assistant professor at the University of Alabama. Ryan M. Cook, PhD, ACS, LPC, is an assistant professor at the University of Alabama. Heather J. Fye, PhD, NCC, LPC, is an assistant professor at the University of Alabama. Correspondence may be addressed to Eric Baltrinic, The University of Alabama, Box 870231, Tuscaloosa, AL 35487, erbaltrinic@ua.edu. 
(Bernard \& Goodyear, 2019). Second, practicum supervisees may become anxious if they are unsure of their roles and what is expected of them by their supervisors and want to feel competent regardless of their actual competency levels (Ellis et al., 2015). Third and finally, the focus and process of supervision changes over time as supervisees develop (Stoltenberg \& McNeill, 2010), including changes to how they function in their expected roles (Bernard \& Goodyear, 2019). These early learning experiences are important for supervisees because they shape their understanding of clinical supervision (Borders, 2019), which they will engage in throughout their field placement experiences and post-degree, prelicensure clinical training (Cook \& Sackett, 2018). Therefore, it is important to understand supervisees' initial understanding of their roles within the counseling practicum environment, including the degree to which these views align with or diverge from their supervisors' (Bernard \& Goodyear, 2019).

\section{Student Learning and the Counseling Practicum Classroom}

For supervision to be a valuable learning experience, it is assumed that supervisees will be able to adequately self-identify and articulate their client concerns as well as their own developmental needs to supervisors (Cook \& Sackett, 2018). However, because practicum supervisees have no prior supervision experience, the way in which they come to understand their roles as supervisees is largely informed by the framework created by the instructor within a practicum course. To that end, practicum course instructors may align their course structure and requirements with accreditation standards (e.g., CACREP, 2015) and professional best practices (e.g., Association for Counselor Education and Supervision Best Practices in Clinical Supervision; Borders et al., 2014) in order to ensure that supervisees are informed of their responsibilities. This information is often conveyed to supervisees via an informed consent or supervision contract (Borders et al., 2014) as well as a course syllabus (CACREP, 2015). However, some supervisees may not fully understand the purpose of supervision nor grasp their roles as supervisees, even though they reviewed an informed consent with their supervisors (Cook et al., 2019).

Counseling practicum courses present students with new opportunities to apply learning from content courses (Moate et al., 2017), refine reflective practice (Neufeldt, 2007), and work with actual clients under supervision (Bernard \& Goodyear, 2019). During this unique and critical learning time, supervisees are closely monitored by supervisors whose expectations and responsibilities are rooted in both supervisors' and supervisees' roles (Bernard \& Goodyear, 2019; CACREP, 2015). Practicum course instructors are charged with facilitating supervisees' learning to develop as professional counselors while safeguarding the welfare of the clients they serve (Borders et al., 2014). Borders (2019) delineated seven process-of-learning principles for use by training supervisors in the supervision classroom. This model is rooted in learning theories, with a particular focus on understanding how supervisors help supervisees in training based on the process of how students learn. We contend that implementation of practicum instruction guided by learning principles could help instructors to scaffold learning processes and teach counseling practicum supervisees about their supervisee roles, which is needed to help them navigate early career challenges (Loganbill et al., 1982).

Ultimately, if supervisees are to be effective with clients, more examination of their understanding of roles and related learning is needed. This information will provide instructors with the necessary knowledge to build effective learning environments and scaffold supervisees' learning experiences in the supervision classroom (Borders, 2019; Moate et al., 2017). Thus, by examining how supervisees understand their supervisee roles, instructors can better teach them how to eventually self-direct their supervision experiences (Stoltenberg \& McNeill, 2010) and effectively utilize supervision (Norem et al., 2006; Pearson, 2004), with the goal of transferring learning from supervision to counseling encounters with clients. 


\section{Counseling Practicum Supervisee Roles}

Novice supervisees (i.e., practicum supervisees) desire to quickly acquire skills so that they can best serve their clients by utilizing the "correct" counseling technique or approach (Stoltenberg \& McNeill, 2010). Further, supervisees experience a high degree of anxiety and confusion as they begin to develop their own counseling style and competencies (Rønnestad \& Skovholt, 2003). Relatedly, Loganbill et al. (1982) suggested that novice supervisees, like counseling practicum supervisees, regularly feel "stuck" in their work with clients and confused as to how best to make progress with their clients. To that end, supervisees benefit from instructors who provide supportive feedback and explicit instructions in a highly structured supervision environment (Ellis et al., 2015; Loganbill et al., 1982; Stoltenberg \& McNeill, 2010) that promotes role clarity (i.e., clearly understanding what is expected and how to meet those expectations).

Failure to determine whether there is alignment between supervisees' and instructors' perspectives on roles may yield unintended but potentially detrimental consequences (Stark, 2017). For example, from an educational perspective, instructors can best attend to their students' learning needs when they understand what it is that their students perceive as being important to their learning (Moate et al., 2017). Furthermore, asking supervisees to engage in evaluations of their performance based on poorly understood roles (Ladany \& Friedlander, 1995) could undermine the purposes of clinical supervision (e.g., professional development, client welfare; Borders et al., 2014) and threaten their right to a fair evaluation as students and supervisees (American Counseling Association [ACA], 2014; CACREP, 2015). Providing supervisees with clear information on their roles can assist with reducing nondisclosure (Cook et al. 2019) and lowering anxiety about their performance (Ellis et al., 2015). These practices allow for safeguarding supervisees and clients, fair supervision evaluation practices (Stark, 2017), and assuring quality supervision instruction grounded in student and instructor perspectives and adult learning processes (Borders, 2019).

Much of the current supervision literature contains guidelines for instructors to effectively conduct supervision (Stark, 2017). For example, Best Practices in Clinical Supervision (Borders et al., 2014) offers specific recommendations for those providing clinical supervision (i.e., supervisors). The expectations of supervisees are implied in the guiding document (e.g., arrive on time to supervision, engage in the supervision process), but the specific roles and responsibilities for supervisees are not explicitly addressed. Whereas others (e.g., Homrich et al., 2014) have conceptualized standards relevant to supervisees' roles in clinical supervision, including self-reflection and self-exploration, communicating information truthfully and accurately, and engaging actively in opportunities for personal and professional development. The importance of supervisees' contributions have also been noted by scholars (e.g., Norem et al., 2006; Stark, 2017; Wilcoxon et al., 2005). For instance, several authors identified supervisee characteristics that are helpful to the learning process in supervision, such as being self-directed, motivated, mature, autonomous, proactive, and open to new learning experiences, all of which are perceived as helping supervisees successfully navigate supervision (Norem et al., 2006; Stark, 2017; Wilcoxon et al., 2005). In an earlier effort to clarify roles and expectations for the supervision process, Munson (2002) identified several supervisee rights, including (a) meeting consistently and regularly with a supervisor, (b) engaging in growth-oriented supervision that considers one's personal privacy, (c) participating in theoretically grounded supervision, (d) receiving clear evaluation criteria and evaluations informed by direct observation, and (e) having a supervisor who is adequately trained. Additionally, Munson suggested that supervisees ought to be able to speak freely in supervision, need encouragement to integrate prior learning from other counseling classes (which supports Borders, 2019), and should remain open and curious about the learning process. Overall, the author's work supports the need for providing supervision based on expectations for both supervisor and supervisee performance. 
Despite these documented guidelines and expectations, there is a notable lack of input from supervisees' perspectives of their roles and related expectations. This is concerning because instructors need to structure their learning environments grounded in evidence supporting student engagement (Malott et al., 2014), which is strengthened by identifying students' prior learning experiences (Borders, 2019).

\section{The Current Study}

Learning to be a supervisee is a process in which counseling students gain experience starting in their practicum courses. It is critical for the supervisor (i.e., instructor) to understand their supervisees' perceptions of their roles in supervision, which have been informed by accreditation requirements (e.g., CACREP, 2015), professional standards (e.g., Best Practices in Clinical Supervision, Borders, 2014), and scholarly literature (e.g., Munson, 2002). Yet, supervisors lack access to information from student perspectives for increasing supervisee engagement and meaningfulness of roles, particularly from the counseling practicum course context where students often experience supervision for the first time. In the current study, we sought to understand the expected roles and responsibilities of new supervisees from the perspectives of supervisees within a counseling practicum course. We also included perspectives from the instructional team (i.e., a doctoral student co-instructor, and a counseling practicum instructor) to illustrate the degree of alignment between instructors and students and to illustrate any nuances between instructor and co-instructor views. Using this research, supervisors and counselor educators may be able to offer developmentally appropriate solutions to address supervisee concerns and to provide support to counseling practicum instructors based on both expert and novice perspectives. Accordingly, our study was guided by the following research question: What are counseling practicum supervisees' views of their roles and responsibilities in the practicum classroom environment?

\section{Method}

Q methodology is a unique research method containing the depth of qualitative data reduction and the objective rigor of by-person factor analysis (Brown, 1996), which can be used effectively in the classroom setting to facilitate students' subject matter understanding (Watts \& Stenner, 2012). Specifically, students' self-perspectives can be revealed in relation to their peers' and instructors' views using $Q$ methodology (Good, 2003). Q methodology has also been used successfully to investigate phenomena in the counselor education classroom (Baltrinic \& Suddeath, 2020) and program settings (Baltrinic et al., 2013) that favor both student and instructor views. Accordingly, we selected $Q$ methodology for this study to obtain perspectives from a participant sample of counseling practicum supervisees and their instructional team.

\section{Concourse and Q Sample}

Specific steps were taken to develop a rigorous $Q$ sample, which is the set of statements used to assist participants with expressing their views on supervisee roles via the Q-sorting process (Brown, 1980). The first step was selecting a concourse, which is a collection of opinion statements about any topic (Stephenson, 1978). Many routes of communication contribute to the form and content of a concourse (Brown, 1980). The concourse for this study was composed of statements we took from select supervision literature and documents (i.e., Borders et al., 2014; Homrich et al., 2014; Kangos et al., 2018; Munson, 2002; Stark, 2017). We searched within these sources and selected concourse statements specifically containing supervision experts' views on supervisees' roles. We needed $100 \%$ consensus on each statement for it to be included in the concourse. The concourse selection process resulted in over 240 concourse statements, which was too many for the final Q sample (Paige \& Morin, 2016).

Second, we proceeded with selecting, evaluating, and reducing the final $Q$ sample items in line with Brown (1980) and Paige and Morin (2016). Initially, we had our first and second authors, Baltrinic and 
Cook, eliminate all duplicate, unclear, fragmented, or unrelated statements from the 240 concourse statements, which resulted in 160 statements. Baltrinic and Cook then used a structured sample design (Brown, 1980) to reduce the 160 concourse statements to a representative 48-item Q sample (Brown, 1980; see Appendix). Representativeness of a $Q$ sample refers to whether the subset of items represent the broader population of statements in the concourse. Third, the 48-item Q sample was then evaluated by three experts (two supervision experts and one $\mathrm{Q}$ methodology expert) using a content validity index (Paige \& Morin, 2016). The expert reviewers rated each of the 48 items on a 4-point scale using three criterion items: 1) Is the statement clear and unambiguous for counselor educators? 2) Is the statement clear and unambiguous for counseling practicum students? and 3) Is the statement distinct from the other statements? Scores across expert reviewers' item ratings were averaged with only scores of 3 (mostly) or 4 (completely) indicating consensus on the content validity index. Items receiving a score of 3 or 4 were included, items receiving a score of 2 (somewhat) were reviewed and modified by our research team for appropriateness, and items receiving a score of 1 (not at all) were discarded from the sample. Accordingly, 45 items received scores of 3 or 4 . Baltrinic completed additional Q sample refinements for the remaining three items that received scores of $2(n=2)$ and $1(n=1)$; two items were rewritten to improve clarity, one duplicate item was eliminated, and one new item was added. All refinements were confirmed by the second author before accepting the items in the final $Q$ sample. For the final step, two of the experts completed $Q$ sorts to ensure the final $Q$ sample facilitated the expression of views on supervisee roles. The results of these two pilot $Q$ sorts were not included in the data analysis.

\section{Participant Sample}

We followed McKeown and Thomas's (2013) recommendations for selecting an intensive participant sample. Therefore, we purposefully selected an intensive participant sample composed of seven master'slevel clinical mental health counseling practicum supervisees, one doctoral co-instructor, and one faculty instructor; all of whom represented a purposeful sample of individuals (Patton, 2015) holding similar theoretical interests and having the ability to provide insight into the topic of investigation (Brown, 1980; McKeown \& Thomas, 2013).

Three of the master's-level counseling students identified as male and four identified as female, and their ages ranged from 23 to 37 years old $(M=30, S D=10.06)$. Regarding race/ethnicity, five of the counseling students identified as European American and two identified as African American. The counselor educator and course instructor identified as a European American male. He holds a PhD in Counselor Education with 5 years of counseling experience and 6 years of supervision experience. Additionally, the instructor is a licensed professional counselor and an Approved Clinical Supervisor, and he publishes regularly on the topic of clinical supervision. The doctoral student co-instructor identified as a European American female who has 3 years of clinical experience as a school counselor and 1 year of supervision experience.

\section{Data Collection}

After receiving IRB approval, Baltrinic collected the initial consents, demographics, Q sorts, and post-Q sort interview data. The students and course instructors $(N=9)$ were asked to rank-order the 48 items under the following condition of instruction: "Select the statements with which you most agree (+4) to those with which you most disagree (-4) that represent a beginning counselor practicum student's supervisee roles." After completing the Q sorts, each participant was asked to provide written responses for the top three items with which they most and least agreed and were asked to comment on any other items of significance. Baltrinic obtained these post-sort questionnaires in person. The purpose of gathering post-sort data is to provide qualitative context for the factor interpretations (Brown, 1996). 


\section{Data Analysis}

Nine Q sorts were completed by the instructional team and the counseling practicum students under a single condition of instruction, all of which were entered into the PQMethod software program V. 2.35 (Schmolck, 2014). A 3-factor solution was selected using the principle components method with varimax rotation, which yields the highest number of significant factor loadings and because Baltrinic, who analyzed the data, was blinded from participants' identifying information (Watts \& Stenner, 2012). Being blinded to participant information renders approaches such as theoretical rotation moot in favor of varimax rotation, given the lack of contextual information related to factor exemplars (i.e., those participants with the highest factor loading on a factor; McKeown \& Thomas, 2013).

\section{Results}

Data analysis revealed three significantly different viewpoints (i.e., Factors 1, 2, and 3) on supervisee roles. For Q methodology, factor loadings are not used for factor interpretation. Instead, the individual significant factor loadings associated with each of the factors are weighted and averaged, resulting in an ideal Q sort representing each factor, which are presented chronologically in a factor array. Factor arrays contain the scores that are used for factor interpretation (see Appendix). Parenthetical reference to specific Q-sample items and their associated factor scores located in the factor array (e.g., Item 23, +2) will be provided within the factor interpretations below. Select participant quotes from post-sort questionnaires are incorporated into the factor interpretations.

\section{Factor 1: The Dutiful Learner}

Factor 1, which we have named the Dutiful Learner, represents a conceptualization of supervisee roles as predominantly adhering to the ethical codes, guidelines, and models of ethical behavior (Item $15,+4)$. One of seven supervisees, the course co-instructor, and the course instructor were significantly associated with Factor 1 (i.e., had factor loadings of 50 or higher; Brown, 1996) with factor loadings of $.70, .82$, and .70, respectively. Supervisee roles attributed to the Dutiful Learner are understood as aspects of the learning process provided that student learning adheres to the code of ethics. Additionally, supervisee roles were viewed in terms of supervisees following the procedures and policies of their graduate programs (Item 36, +4), which as one participant noted "are really non-negotiable." Supervisee roles, including the demonstration of healthy professional boundaries in supervision sessions and with clients, were also highly preferred by participants aligning with this factor (Item $25,+4)$. When reflecting on Item 25, the supervisee participant emphasized, "Healthy boundaries are paramount for legally and emotionally protecting oneself." Finally, the Dutiful Learner viewpoint entails emphasis on the importance of supervisees arriving on time for supervision (Item $7,+3$ ), including the need to be prepared for every supervision session (e.g., individual, triadic, group; Item 18, +2).

Participants ascribing to the Dutiful Learner view of supervisee roles were less concerned about the demonstration of awareness of strengths and weaknesses to instructors (Item 1, 0), which according to one participant would "occur as part of the process over time." Dutiful Learners are viewed as favoring ethically guided supervisee roles versus simply being pleasant to work with in supervision (Item 30, -4) or gratuitously asking questions regarding counseling-related issues (Item 32, -3). Dutiful Learner viewpoints may be related to having a sense of responsibility for other supervisees' learning that includes a desire for students to develop a strong ethical compass, which is needed "throughout their development as counselors." For example, according to the co-instructor, who noted in her postsort interview questionnaire, "It seems items I ranked highest were 'rules' and 'guidelines,' which I feel is influenced by the need to be an ethical practitioner and influenced by being in the co-teacher role." 
Overall, supervisees, according to the course instructor, are reminded to "trust the process" in their beginning roles, given it is most critical that they have a "willingness" to learn.

\section{Factor 2: The Discerning Learner}

Factor 2 characterized supervisees as having a penchant for seeking feedback, a spirit of willingness, and thoughtful reasoning; therefore, we have named this factor the Discerning Learner. For Factor 2, three of the seven supervisees had significant factor loadings (.67, .83, and .58 , respectively). In general, the Discerning Learner represents a conceptualization of supervisee roles in which supervisees feel their supervisors provide them with feedback about counseling skills (Item 40, +4 ), which according to one participant is the "purpose of supervision." The supervisees whose viewpoints aligned with this factor valued supervisee roles that included asking for help when needed (Item 35, +4), which is related to recognizing and regularly seeking feedback from their supervisors (Item 20, +2 ). Throughout the supervision process, Discerning Learners are viewed as valuing organization and exercising good judgement when approaching supervision situations (Item 43,+4). Overall, a willingness to work with their supervisors (Item 33, +3) was deemed important given the interpersonal nature of the supervision process.

Further, the Discerning Learner view favored the acquisition of counseling skills as central to supervisee roles. With a focus on skill acquisition, the need to manage ambiguity and uncertainty as a function of their roles was considered less important for Discerning Learners (Item 14, -4). As one participant noted, "The whole point of supervision is to take what the supervisor is telling us and apply it to our practice." Additionally, for participants whose views aligned to this factor, recognizing and managing anxiety (Item 12,-4) was not considered central to supervisee roles in practicum because anxiety is commonly accepted as "part of the learning process in supervision." One participant normalized the presence of anxiety and the need to "discuss it in supervision," further suggesting, "It is good to express anxiety about the supervision process instead of bottling it in." Overall, supervisees who view supervisee roles from the viewpoint of the Discerning Learner accept anxiety and ambiguity as those things that "should be expected" when using good judgement to acquire and refine counseling skills and initiate discussions about the process in supervision.

\section{Factor 3: The Expressive Learner}

Factor 3 favored the personal and interpersonal expression of needs in the interest of learning; therefore, we have named this factor the Expressive Learner. Three of seven supervisees had significant factor loadings on Factor $3(.73, .50$, and .63, respectively). Supervisees whose views aligned with the Expressive Learner factor favored supervisee roles emphasizing opportunities to be vulnerable in sessions with their supervisor (Item 34,+4). This factor entailed supervisee acknowledgment of the emotional context for learning and growth; as suggested by one supervisee, "If I don't feel vulnerable, then I'm not going to have an experience where I truly learn." Another non-traditional age male supervisee elaborated, "Older students often bring work experience and personal experience to the supervisee role," which according to another participant (also a non-traditional male student) means that "If a supervisee is unable to be open and honest (despite previous experiences), then no progress is made towards professional growth." Additionally, managing personal and interpersonal issues was deemed important for supervisee roles (Item 22, +4). As one supervisee noted, "Although it can be difficult to manage various life roles, it is important not to let those life roles interfere." The Expressive Learner is further conceived as valuing the demonstration of verbal communication skills (Item $28,+3$ ) and having the ability to take multiple perspectives (Item $21,+3$ ), both of which were deemed essential for "welcoming and responding to supervisors" critical feedback," especially with challenging cases. 
The underlying sentiment of feeling empowered by supervisors (Item $45,+2$ ) was deemed important because "feeling empowered will drive you to continue growing your skills." Overall, the personal and interpersonal nature of supervision and supervisees' roles was distinguishing for this factor.

Supervisees ascribing to the Expressive Learner factor expected that the ability to speak freely in supervision (Item 2, -3) is an assumed role of supervisees. As one participant explained, "It is important for me to say exactly what I'm feeling so my supervisor can give me their perspective and help me work through any issues." Similarly, identifying supervisee developmental needs (Item 9, -4) is viewed as part of all supervision that should be initiated by the instructor at the beginning stage of supervision. For example, as one supervisee noted, "Because I am a student, I want my supervisor to initiate discussions" related to developmental needs "and then guide me with questions." Finally, active participation in supervision (Item 42, -2) was viewed as less important because it is "expected," and although supervisees should work collaboratively, "establishing tasks and goals should first be initiated by the supervisor," a point echoed by all supervisees associated with Factor 3. It seems then that Expressive Learners are interpersonally attuned and focused and most responsive when supervisee roles are activated through initial supervisor prompts.

\section{Discussion}

The purpose of the current study was to examine the roles of supervisees as perceived from the multiple viewpoints of counseling practicum supervisees, a doctoral co-instructor, and a faculty instructor. Collectively, our findings reveal three different viewpoints (i.e., factors) of supervisees' roles and responsibilities. Interestingly, only one of the seven supervisees' views of these roles aligned with the views of the doctoral co-instructor and practicum course instructor. Even though the instructors acculturated the supervisees to their responsibilities in relatively the same way (e.g., university supervision contract, course syllabus) and used methods that aligned with accreditation guidelines, professional standards, and best practices in supervision, the majority of students still made meaning of these roles as supervisees in ways that differed from the instructors' viewpoint. At the same time, supervisees deemed it important to convey their own professional competencies to their evaluative supervisors (Cook et al., 2019). As we will discuss below, course instructors who hope to better attend to the learning needs of all students and understand how their students perceive their own roles in clinical supervision can integrate details from the three factors (the Dutiful Learner, the Discerning Learner, and the Expressive Learner) into their instruction practices.

Participants whose views most strongly aligned to the Dutiful Learner factor perceive the most important aspect of supervisee roles as adhering to ethical codes and course requirements. For Dutiful Learners, supervisee roles parallel the concrete expectations often outlined in a supervision contract (Ellis, 2017) or course syllabus. That is, having clear expectations of clinical supervision and an operational understanding of the structural aspects of clinical supervision were endorsed as the strongest expectations of Dutiful Learners. Additionally, participants who conceptualized supervisee roles in terms of Factor 1 believe supervisees will gain insight into their own skills and competencies over time as they develop in their roles (Loganbill et al., 1982). However, having a foundational understanding of how to utilize clinical supervision as well as their rights as supervisees in clinical supervision (Munson, 2002) may be most critical for Dutiful Learners (Stoltenberg \& McNeill, 2010). Accordingly, Dutiful Learners may find the explicit instructions for supervision helpful for managing the anxieties and uncertainties that are often experienced by new supervisees (Loganbill et al., 1982). Specific aspects to focus on for Dutiful Learners' roles would be to review ethical guidelines, course requirements, and strategies for coming prepared to supervision. 
Discerning Learners (Factor 2) favor their roles as active participants in the supervision process, which they perceive as a relational process between supervisee and supervisor, and student and instructor. That is, Discerning Learners perceive a collaborative relationship between supervisee and supervisor as being central to their professional development and their counseling work with clients. This factor best reflects the supervisee working alliance (Bordin, 1983), in which creating a strong emotional bond between supervisors and supervisees and mutual agreement on goals and tasks is most important to positive outcomes in supervision (e.g., intentional nondisclosure, role ambiguity; Cook \& Welfare, 2018; Ladany \& Friedlander, 1995). Discerning Learners also acknowledge that anxiety is a common characteristic of being a supervisee, which is somewhat expected given the participants' developmental level (i.e., novice supervisees; Rønnestad \& Skovholt, 2003; Stoltenberg \& McNeill, 2010). However, they view acknowledging this anxiety to their supervisors as helpful. Finally, Discerning Learners perceive discussing cultural identities as being relevant to their role as supervisees, although one supervisee stated culture should only be discussed with a client "when relevant to their counseling work."

Expressive Learners (Factor 3) perceive the role of a supervisee as being vulnerable with and openly disclosing information to their supervisor, demonstrating the ability to take multiple perspectives with their clients, and feeling empowered by their supervisors. These findings align with Cook et al. (2018), who investigated supervisees' perceptions of power dynamics in clinical supervision. Further, the Expressive Learner factor represents views most aligned with tenets of feminist supervision (e.g., Porter, 1995; Porter \& Vasquez, 1997). Porter (1995) noted that supervisors empower their supervisees by creating a safe environment and valuing their supervisees' perspectives with the goal of facilitating their supervisees' autonomy, although there is substantial evidence that counseling students, such as practicum supervisees, withhold information from their supervisors (e.g., Cook \& Welfare, 2018; Cook et al., 2019). Expressive Learners view learning as a self-directed process within supervision, which also suggests they perceive themselves as active contributors to clinical supervision (Stark, 2017). At the same time, Expressive Learners also look to their supervisors to initiate discussion about their developmental needs and to provide insights into their opportunities for professional growth. This viewpoint aligns with that of Stoltenberg and McNeill (2010), who contend that supervisors can help novice supervisees to gain awareness into their own developmental needs through questioning and supportive feedback.

\section{Implications for Practicum Instructors}

Practicum course instructors often have the responsibility to teach supervisees about their roles and responsibilities as they align with accreditation standards (i.e., CACREP, 2015), professional standards (i.e., ACES Best Practices in Clinical Supervision; Borders et al., 2014), and ethical guidelines (i.e., ACA, 2014). To that end, practicum instructors must convey their expectations for students in their classroom and attend to the diverse learning needs of all their students. Our findings suggest supervisees understand their roles and responsibilities in three different ways, which at times differ from those of the course instructors. Instructors must be able to provide sufficient, appropriate, and meaningful feedback to all supervisees in their class (Borders, 2019) to ensure they are adequately able to successfully navigate supervision in the classroom and in future supervision experiences. Thus, we offer practicum instruction strategies based on the three supervisees' viewpoints of their roles (i.e., factors). For example, instructors can assess supervisees' understanding of their prior experiences with evaluative relationships (i.e., educational, personal, professional; Borders, 2019) and how those experiences might be similar or different to their current experience in the counseling practicum course.

Our findings also connect with evidence-based processes for how students learn. As you may recall from the literature review, Borders (2019) delineated seven principles rooted in learning theories, with a particular focus on understanding how to help supervisees based on the process of how students learn. 
These seven principles are connected to our findings and noted in parentheses (e.g., Principle 1) within the text that follows. Specifically, instructors can use characteristics of the three factors, along with the seven learning principles, to inform counseling practicum instruction and doctoral supervision strategies. For example, instructors can help Dutiful Learners identify ethical dilemmas (e.g., risk assessment, mandated reporting, healthy boundaries between client and counselor) and ways to discuss solutions with their supervisors by watching segments of counseling sessions (Principle 1). Instructors can then ask supervisees to use ethical decision-making models to connect practice to theory (Principle 2), and they can help supervisees to identify needed skills, including situations in which these skills are most needed (Principle 4 and 7). Instructors can observe supervisees' skills practice and direct doctoral co-teachers to identify ways for the supervisees to improve practice and convey ethical dilemmas to supervisors (e.g., site supervisor, course instructor). As supervisees understand their roles, they can pursue role-playing ethical dilemmas and learn how to receive and respond to feedback after each role-play within a low-risk classroom setting (Principle 3). Overall, supervisees and doctoral co-teachers should receive scaffolded instructor feedback to help them better correct any errors (Principle 5).

Discerning Learners prefer presenting counseling work to their supervisors and discussing related feedback about their counseling skills, which can be done based on a mutual understanding and appreciation of supervisees' roles. Thus, instructors should consider reviewing with supervisees the counseling skills learned in previous classes (Principle 1; Borders, 2019), including assessing supervisees' comfort level with using specific counseling skills. To that end, instructors can ask supervisees to identify and name specific skills in their counseling work as well as their peers' counseling work during role-plays or actual counseling sessions (Principle 5). Additionally, because Discerning Learners value discussing their anxiety and issues of culture with their supervisors, instructors can include a question about supervisees' anxiety in case presentation forms, which could then be used as a starting point to facilitate any individual or group discussions. Identifying and addressing anxiety (Bernard \& Goodyear, 2019) is important because supervisees need to know how to broach difficult topics with clients (Day-Vines et al., 2020), and instructors need to model that broaching for doctoral co-teachers and supervisees (Principle 6).

Of the factors identified in the current study, the Expressive Learners prefer a self-directed role when engaging in their supervision experience. Expressive Learners prefer a learning environment in which disclosure is encouraged, vulnerability is validated, and empowerment is facilitated. Accordingly, instructors need to assess Expressive Learners' motivation level, which is a critical driver for learning new content (Principle 3; Borders, 2019) and for understanding supervisees' capacities to self-direct their learning experiences (Principle 7). Instructors can assist Expressive Learners with developing learning goals that can include strategies for both collaboration and self-direction (Principle 7). Additionally, instructors may use specific supervision techniques, such as interpersonal process recall (Kagan, 1980), to gain insight into supervisees' perceptions of their skills and to encourage their disclosure-related skill acquisition (Principle 4). This is important because Expressive Learners are willing to discuss their concerns when prompted by supervisors. Finally, instructors may also consider using the Power Dynamics in Supervision Scale (Cook et al., 2018) to assess supervisees' perspectives of being vulnerable or empowered.

\section{Limitations and Future Research}

Researchers who use $Q$ methodology gather and analyze data to reveal common viewpoints among participants, and in this case within a single counseling practicum course. As such, the $Q$ factors in this study do not generalize (Brown, 1980) similarly to the findings in widescale quantitative studies. We caution readers against interpreting factors as being "better or worse" or "right or wrong" for other practicum courses. However, similar factors may plausibly exist among supervisees' views in other 
counselor education practicum courses. In this way, any similarities from our findings to other sites is seen more as a matter of shared experiences rather than generalized findings (Stephenson, 1978). The low number of participants in the current study may be viewed as a limitation. However, similar to Baltrinic and Suddeath (2020), the instructors and student participants in the current study represented a purposeful sample of sole interest (Brown, 1980), revealing robust factors within a counselor education classroom (i.e., the unit of analysis). Nevertheless, future research could include larger numbers of participants across multiple practicum courses, which may increase the potential for revealing the existence of additional factors. Researchers are encouraged to test propositions by having supervisees complete Q-sorts with the current $Q$ sample within and across other counseling subspeciality areas as well. Researchers can also use qualitative or case study methods to investigate supervisees' views from practicum through the completion of internship.

\section{Conclusion}

In conclusion, practicum course instructors can incorporate the current findings into their supervision pedagogy. Using student-generated factors can help practicum course instructors guide supervisees to (a) develop skills grounded in a clear understanding of their roles and related approaches to learning, (b) select and incorporate supervisor feedback about the goals and tasks of supervision, and (c) identify areas of growth based on the alignment of supervisees' and instructors' role perspectives.

\section{Conflict of Interest and Funding Disclosure}

The authors reported no conflict of interest or funding contributions for the development of this manuscript.

\section{References}

American Counseling Association. (2014). ACA code of ethics.

Baltrinic, E. R., \& Suddeath E. G. (2020). A Q methodology study of a doctoral counselor education teaching instruction course. The Professional Counselor, 10(4), 472-487. https://doi.org/10.15241/erb.10.4.472

Baltrinic, E. R., Waugh, J. A., \& Brown, S. R. (2013). Faculty and student perspectives on what helps counselor education doctoral students towards program completion. Operant Subjectivity: The International Journal of Q Methodology, 36(4), 253-271. https://doi.org/10.15133/j.os.2012.014

Bernard, J. M., \& Goodyear, R. K. (2019). Fundamentals of clinical supervision (6th ed.). Pearson.

Borders, L. D. (2019). Science of learning: Evidence-based teaching in the clinical supervision classroom. Counselor Education and Supervision, 58(1), 64-79. http://doi.org/10.1002/ceas.12124

Borders, L. D., Glosoff, H. L., Welfare, L. E., Hays, D. G., DeKruyf, L., Fernando, D. M., \& Page, B. (2014). Best practices in clinical supervision: Evolution of a counseling specialty. The Clinical Supervisor, 33(1), $26-44$. https://doi.org/10.1080/07325223.2014.905225

Bordin, E. S. (1983). A working alliance based model of supervision. The Counseling Psychologist, 11(1), 35-42. https://doi.org/10.1177\%2F0011000083111007

Brown, S. R. (1980). Political subjectivity: Applications of Q methodology in political science. Yale University Press.

Brown, S. R. (1996). Q methodology and qualitative research. Qualitative Health Research, 6(4), 561-567. https://doi.org/10.1177/104973239600600408

Cook, R. M., McKibben, W. B., \& Wind, S. A. (2018). Supervisee perception of power in clinical supervision: The Power Dynamics in Supervision Scale. Training and Education in Professional Psychology, 12(3), 188195. https://doi.org/10.1037/tep0000201

Cook, R. M., \& Sackett, C. R. (2018). Exploration of prelicensed counselors' experiences prioritizing information for clinical supervision. Journal of Counseling E Development, 96(4), 449-460. https://doi.org/10.1002/jcad.12226 
Cook, R. M., \& Welfare, L. E. (2018). Examining predictors of counselor-in-training intentional nondisclosure. Counselor Education and Supervision, 57(3), 211-226. https://doi.org/10.1002/ceas.12111

Cook, R. M., Welfare, L. E., \& Sharma, J. (2019). Exploring supervisees' in-session experiences of utilizing intentional nondisclosure. The Clinical Supervisor, 38(2), 202-221. http://doi.org/10.1080/07325223.2019.1608344

Council for Accreditation of Counseling and Related Educational Programs. (2015). 2016 CACREP Standards. http://www.cacrep.org/wp-content/uploads/2017/08/2016-Standards-with-citations.pdf

Day-Vines, N. L., Cluxton-Keller, F., Agorsor, C., Gubara, S., \& Otabil, N. A. A. (2020). The multidimensional model of broaching behavior. Journal of Counseling \& Development, 98(1), 107-118. https://doi.org/10.1002/jcad.12304

Ellis, M. V. (2017). Clinical Supervision Contract \& Consent Statement and Supervisee Rights and Responsibilities. The Clinical Supervisor, 36(1), 145-159. https://doi.org/10.1080/07325223.2017.1321885

Ellis, M. V., Hutman, H., \& Chapin, J. (2015). Reducing supervisee anxiety: Effects of a role induction intervention for clinical supervision. Journal of Counseling Psychology, 62(4), 608-620. http://doi.org/10.1037/cou0000099

Good, J. M. M. (2003). William Stephenson, quantum theory, and Q methodology. Operant Subjectivity, 26(4), 142-156. http://doi.org/10.15133/j.os.2003.009

Homrich, A. M., DeLorenzi, L. D., Bloom, Z. D., \& Godbee, B. (2014). Making the case for standards of conduct in clinical training. Counselor Education and Supervision, 53(2), 126-144. https://doi.org/10.1002/j.1556-6978.2014.00053.x

Kagan, N. (1980). Influencing human interaction - Eighteen years with IPR. In A. K. Hess (Ed.), Psychotherapy supervision: Theory, research and practice (pp. 262-283). Wiley.

Kangos, K. A., Ellis, M. V., Berger, L., Corp, D. A., Hutman, H., Gibson, A., \& Nicolas, A. I. (2018). American Psychological Association guidelines for clinical supervision: Competency-based implications for supervisees. The Counseling Psychologist, 46(7), 821-845. http://doi.org/10.1177/0011000018807128

Ladany, N., \& Friedlander, M. L. (1995). The relationship between the supervisory working alliance and trainees' experience of role conflict and role ambiguity. Counselor Education and Supervision, 34(3), 220-231. https://doi.org/10.1002/j.1556-6978.1995.tb00244.x

Loganbill, C., Hardy, E., \& Delworth, U. (1982). Supervision: A conceptual model. The Counseling Psychologist, 10(1), 3-42. http://doi.org/10.1177/0011000082101002

Malott, K. M., Hridaya Hall, K., Sheely-Moore, A., Krell, M. M., \& Cardaciotto, L. (2014). Evidence-based teaching in higher education: Application to counselor education. Counselor Education and Supervision, 53(4), 294-305. https://doi.org/10.1002/j.1556-6978.2014.00064.x

McKeown, B., \& Thomas, D. B. (2013). Q methodology (2nd ed.). SAGE.

Moate, R. M., Holm, J. M., \& West, E. M. (2017). Perceived helpfulness of teachers in clinical courses. The Professional Counselor, 7(2), 155-168. http://doi.org/10.15241/rmm.7.2.155

Munson, C. E. (2002). Handbook of clinical social work supervision (3rd ed.). Haworth Press.

Neufeldt, S. A. (2007). Supervision strategies for the first practicum (3rd ed.). American Counseling Association.

Norem, K., Magnuson, S., Wilcoxon, S. A., \& Arbel, O. (2006). Supervisees' contributions to stellar supervision outcomes. Journal of Professional Counseling: Practice, Theory E Research, 34(1-2), 33-48. https://doi.org/10.1080/15566382.2006.12033822

Paige, J. B., \& Morin, K. H. (2016). Q-sample construction: A critical step for a Q-methodological study. Western Journal of Nursing Research, 38(1), 96-110. https://doi.org/10.1177/0193945914545177

Patton, M. Q. (2015). Qualitative research and evaluation methods (4th ed.). SAGE.

Pearson, Q. M. (2004). Getting the most out of clinical supervision: Strategies for mental health counseling students. Journal of Mental Health Counseling, 26(4), 361-373. http://doi.org/10.17744/mehc.26.4.ttju8539ke8xuq6

Porter, N. (1995). Supervision of psychotherapists: Integrating anti-racist, feminist, and multicultural perspectives. In H. Landrine (Ed.), Bringing cultural diversity to feminist psychology: Theory, research, and practice (pp. 163-175). American Psychological Association. http://doi.org/10.1037/10501-008

Porter, N., \& Vasquez, M. (1997). Covision: Feminist supervision, process, and collaboration. In J. Worell \& N. G. Johnson (Eds.), Shaping the future of feminist psychology: Education, research, and practice (pp. 155-171). American Psychological Association. https://doi.org/10.1037/10245-007 
Rønnestad, M. H., \& Skovholt, T. M. (2003). The journey of the counselor and therapist: Research findings and perspectives on professional development. Journal of Career Development, 30(1), 5-44. http://doi.org/10.1177/089484530303000102

Schmolck, P. (2014). PQMethod (Version 2.35). [Computer Software]. http://schmolck.userweb.mwn.de/qmethod Stark, M. D. (2017). Assessing counselor supervisee contribution. Measurement and Evaluation in Counseling and Development, 50(3), 170-182. http://doi.org/10.1080/07481756.2017.1308224

Stephenson, W. (1978). Concourse theory of communication. Communication, 3(1), 21-40.

Stoltenberg, C. D., \& McNeill, B. W. (2010). IDM supervision: An integrative developmental model for supervising counselors $\mathcal{E}$ therapists (3rd ed.). Routledge.

Watts, S., \& Stenner, P. (2012). Doing Q methodological research: Theory, method and interpretation. SAGE.

Wilcoxon, S. A., Norem, K., \& Magnuson, S. (2005). Supervisees' contributions to lousy supervision outcomes. Journal of Professional Counseling: Practice, Theory \& Research, 33(2), 31-49. https://doi.org/10.1080/15566382.2005.12033816 


\section{Appendix \\ Q Sample Statements and Factor Array}

\begin{tabular}{|c|c|c|c|c|}
\hline$\#$ & Statement & F1 & F2 & F3 \\
\hline 1 & Demonstrates an awareness of their own strengths and weaknesses. & 0 & 3 & 2 \\
\hline 2 & Feels able to speak freely in supervision sessions. & 1 & 1 & -3 \\
\hline 3 & Reads up on topics in their area of practice. & -3 & -1 & -2 \\
\hline 4 & Communicates information truthfully and accurately. & 3 & 3 & 0 \\
\hline 5 & Manages personal wellness (physically, spiritually, psychologically, and socially) with supervisor. & 0 & -2 & 1 \\
\hline 6 & Develops specific realistic and measurable goals for supervision with the supervisor. & 1 & -2 & -1 \\
\hline 7 & Arrives on time for supervision. & 3 & -3 & 0 \\
\hline 8 & Feels their perspectives and experiences were valued by supervisors in supervision sessions. & 0 & 1 & 0 \\
\hline 9 & Identifies their own developmental needs. & -1 & 0 & -4 \\
\hline 10 & Broaches difficult topics in supervision, such as issues pertaining to culture, race, or ethnicity. & 3 & 0 & 3 \\
\hline 11 & Listens attentively to supervisor. & -2 & 0 & -4 \\
\hline 12 & Recognizes and manages their anxiety about the supervision process. & 0 & -4 & 1 \\
\hline 13 & Initiates discussions related to the supervisory relationship. & -3 & -2 & -4 \\
\hline 14 & Manages ambiguity and uncertainty. & 1 & -4 & -1 \\
\hline 15 & Adheres to the ethical codes, guidelines, and models of ethical behavior. & 4 & 0 & 2 \\
\hline 16 & Feels their cultural identities are valued by a supervisor. & 2 & -4 & 2 \\
\hline 17 & Demonstrates a willingness to grow. & 2 & 2 & 3 \\
\hline 18 & $\begin{array}{l}\text { Prepares for each supervision session relevant to the supervision format (e.g., individual, } \\
\text { triadic, group). }\end{array}$ & 2 & -2 & 0 \\
\hline 19 & Feels able to set goals independently. & -4 & -2 & -3 \\
\hline 20 & Recognizes and seeks regular and ongoing feedback. & -2 & 2 & -2 \\
\hline 21 & Demonstrates an ability to see things from multiple perspectives. & 1 & 0 & 3 \\
\hline 22 & Manages personal mental health, emotional problems, stress, and interpersonal issues. & 1 & 1 & 4 \\
\hline 23 & Identifies how own biases interfere with development. & 2 & 1 & 1 \\
\hline 24 & Collaborates on setting agendas for supervision sessions. & -2 & -3 & -3 \\
\hline 25 & Demonstrates healthy professional boundaries in supervision sessions and with clients. & 4 & 2 & 2 \\
\hline 26 & Feels their time in supervision sessions is respected by supervisors. & 0 & -1 & -1 \\
\hline 27 & Raises respectfully any points of disagreement with supervisor's opinions. & -2 & -2 & 0 \\
\hline 28 & Demonstrates verbal communication skills in supervision. & -1 & -1 & 3 \\
\hline 29 & Integrates feedback from supervisor into their clinical work. & 2 & 3 & 2 \\
\hline 30 & Is pleasant to work with in supervision. & -4 & -1 & 1 \\
\hline 31 & Maintains an open and curious view of learning. & 2 & 1 & -2 \\
\hline 32 & Asks thoughtful questions in supervision regarding counseling-related issues. & -3 & 2 & 4 \\
\hline
\end{tabular}




\begin{tabular}{|c|l|c|c|c|}
\hline$\#$ & \multicolumn{1}{|c|}{ Statement } & F1 & F2 & F3 \\
\hline 33 & Works willingly with the supervisor. & -1 & 3 & -3 \\
\hline 34 & Feels like they can be vulnerable in supervision sessions with their supervisor. & 0 & 0 & 4 \\
\hline 35 & Asks for help when needed. & 1 & 4 & -2 \\
\hline 36 & Follows the procedures and policies of the graduate program. & 4 & -1 & 0 \\
\hline 37 & $\begin{array}{l}\text { Integrates prior learning from other counseling classes such as microskills and theories into } \\
\text { linical work. }\end{array}$ & -1 & 2 & 1 \\
\hline 38 & Speaks freely and professionally about problem client cases in supervision. & 1 & 1 & -1 \\
\hline 39 & Supports the learning process of others. & -3 & -3 & 0 \\
\hline 40 & Feels supervisors provide feedback about counseling skills. & -1 & 4 & -1 \\
\hline 41 & Solicits feedback from peers. & -2 & -1 & -2 \\
\hline 42 & Participates actively in supervision sessions. & 3 & 2 & -2 \\
\hline 43 & Uses organized reasoning and good judgement to assess and respond to situations. & 0 & 4 & -1 \\
\hline 44 & Seeks challenges by attempting tasks that are perceived to be difficult. & -4 & -3 & -1 \\
\hline 45 & Feels empowered by their supervisor in supervision sessions. & -1 & 0 & 2 \\
\hline 46 & Takes responsibility for consequences of their behavior. & 0 & 1 & 0 \\
\hline 47 & Fosters the supervisory relationship including agreement on emotional connection, goals, and tasks. & -2 & -1 & 0 \\
\hline 48 & Discusses their impairments, blind spots, and other limitations with supervisor. & -1 & 0 & 1 \\
\hline
\end{tabular}

